\title{
Simple, reproducible, and consistent physiology: The argument for single-ventricle repair in critically ill neonates with Ebstein anomaly
}

John D. Cleveland, MD, and Vaughn A. Starnes, MD

Feature Editor's Introduction-Ebstein anomaly is a complex heterogeneous congenital heart defect that involves the tricuspid valve and right ventricle. The clinical presentation is determined by the degrees of tricuspid valve displacement and regurgitation, right ventricular outflow tract obstruction, functional right ventricle size, and septal displacement affecting left ventricular function and cardiac output.

Given its rarity, individual and institutional experiences with Ebstein anomaly are generally limited, especially in neonates. A recent study from the Society of Thoracic Surgeons demonstrated that the average number of neonates treated was $<40$ yearly. Moreover, it showed variations in treatment strategies among centers that likely reflected both diverse anatomy and management opinions. Finally, it showed persistent high operative mortality $(>25 \%)$ with these different strategies; all indicating continuous struggle and knowledge gaps when it comes to this complex defect.

Dr Vaughn Starnes has provided a vital contribution to these patients by proposing his operation that includes tricuspid valve exclusion with fenestrated patch (eliminating septal shift that interferes with left ventricular function), and a modified Blalock-Taussig shunt. This operation can be reproducible and applicable to all neonates, although it is naturally associated with the usual early and late single-ventricle palliation complications.

Drs Cleveland and Starnes provide an excellent review of the management strategy of neonates with Ebstein anomaly at Children's Hospital Los Angeles and outline their philosophy toward early intervention ( $<72$ hours) in selected neonates with hemodynamic compromise, anatomic atresia, or circular shunt. They describe their initial management and decision-making process, and

From the Division of Cardiac Surgery, Department of Surgery, Children's Hospital Los Angeles, Los Angeles, Calif.

Received for publication Feb 2, 2021; accepted for publication Feb 3, 2021; available ahead of print April 3, 2021

Address for reprints: John D. Cleveland, MD, Division of Cardiac Surgery, Department of Surgery, Children's Hospital Los Angeles, 4650 Sunset Blvd, Mailstop \#66, Los Angeles, CA 90033 (E-mail: jcleveland@chla.usc.edu).

JTCVS Techniques 2021;10:428-32

2666-2507

Copyright $@ 2021$ The Author(s). Published by Elsevier Inc. on behalf of The American Association for Thoracic Surgery. This is an open access article under the CC BY-NC-ND license (http://creativecommons.org/licenses/by-nc-nd/4.0/).

https://doi.org/10.1016/j.xjtc.2021.02.051

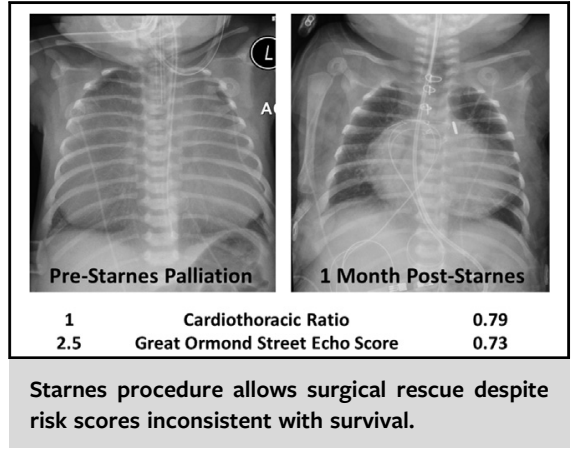

CENTRAL MESSAGE

Newborn infants with severe

Ebstein anomaly represent a

high-risk group of patients who

benefit from the consistent

physiology of right ventricle

exclusion when operative inter-

vention is necessary.

discuss the physiologic rational that favors Starnes operation over primary biventricular repair in their experience. They also report clinical outcomes from their relatively large single-institution experience that include information about survival, right ventricular remodeling, and possibility of later conversion to 1.5 or biventricular repair.

I enjoyed learning from Dr Starnes's experience in this challenging and rare patient population and I believe that readers will find this review very valuable and stimulating. Bahaaldin Alsoufi, MD

Neonates diagnosed with Ebstein anomaly, either prenatally or postnatally, are a heterogenous group of patients. Some infants present in extremis and require extensive resuscitation to survive the first day of life, whereas others are cared for with minimal medical support. The first step in management following birth and medical stabilization is to determine whether a neonatal intervention will be necessary. Intervention is obligate for newborn infants with anatomic pulmonary atresia and circular shunts secondary to pulmonary insufficiency. These infants are typically hemodynamically unstable and undergo an operation within 48 to 72 hours of birth at our institution. We also believe that 


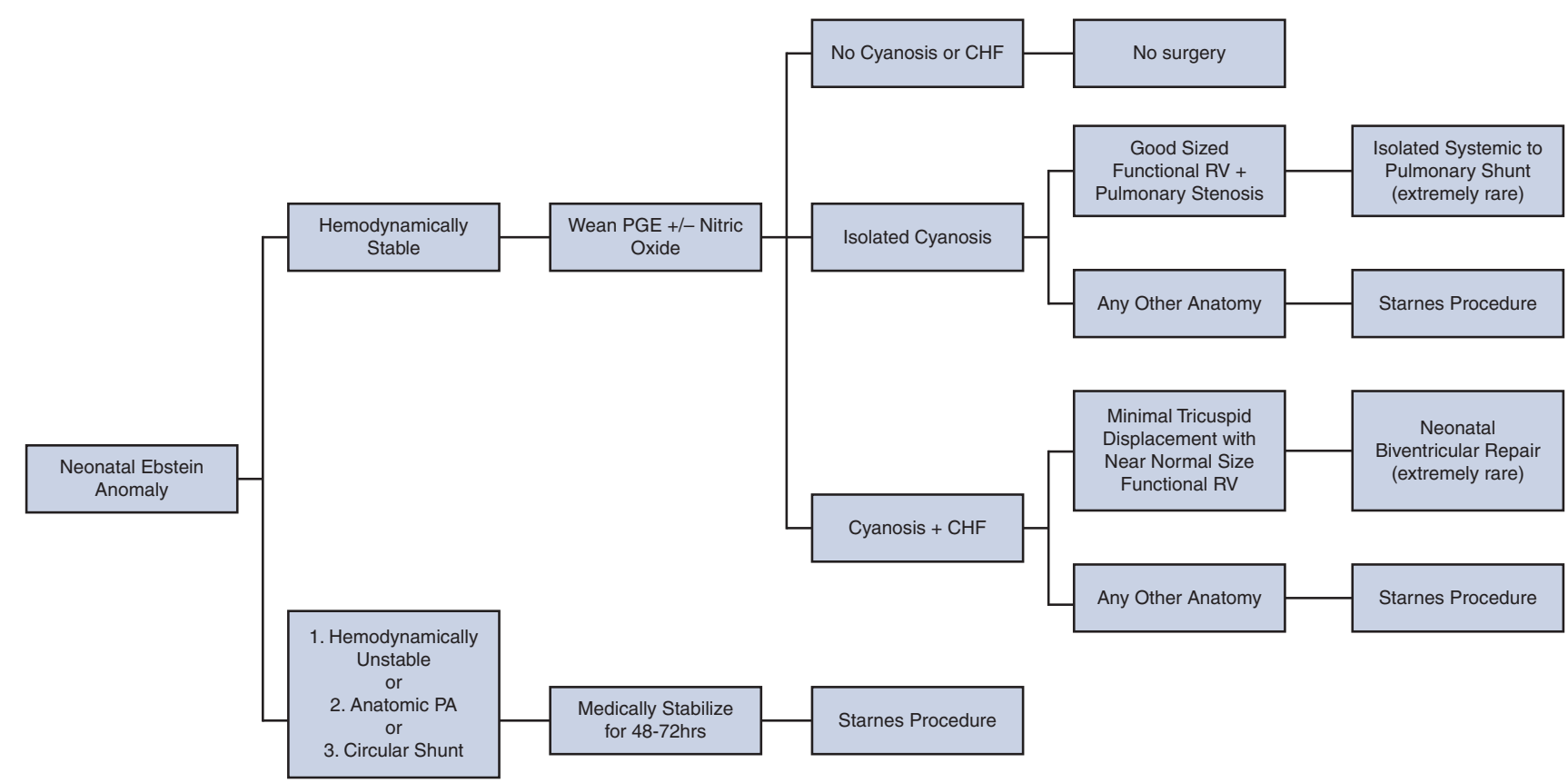

FIGURE 1. Institutional management algorithm for neonates diagnosed with Ebstein anomaly. $P A$, Pulmonary atresia; $P G E$, prostaglandin; $C H F$, congestive heart failure; $R V$, right ventricle.

newborn infants who have an ongoing requirement for vasopressors to maintain hemodynamic stability should undergo early intervention $(<72$ hours) regardless of pulmonary valve status. Hemodynamic instability is the result of negative interventricular interactions causing a reduction in left ventricular (LV) output. ${ }^{1}$ The only manner to alter it is with an effective surgical procedure to decompress the right ventricle (RV).

For the newborn infant who can be stabilized with either a functioning pulmonary valve or functional pulmonary atresia, a trial of prostaglandin wean is warranted once pulmonary vascular resistance falls. Our institution will often use nitric oxide to hasten a drop in pulmonary vascular resistance and sooner delineate those patients who can tolerate ductus arteriosus closure without significant cyanosis or heart failure. Such patients can be discharged home. Approximately half $(46 \%)$ of newborn infants diagnosed with Ebstein anomaly ultimately require some form of neonatal intervention. ${ }^{2}$ We seek to offer an opinion regarding the best method to manage these children with an emphasis on single-ventricle palliation.

All medical and surgical efforts to salvage critically ill newborn infants with Ebstein anomaly produced uniformly dismal results before 1991. That year, the first report was published of a surgery to create life-sustaining singleventricle physiology in a series of 5 neonates. The original Starnes procedure involved tricuspid valve closure, right atrial (RA) reduction plasty, and systemic to pulmonary artery (PA) shunt. All patients in the original report survived. ${ }^{3}$
It was a revolutionary paradigm shift in care. Knott-Craig and colleagues ${ }^{4}$ subsequently reported successful biventricular repair (BVR) in 3 critically ill neonates in 2000 via tricuspid valve reconstruction to a monocusp, right ventriculorrhaphy, subtotal atrial septal defect closure, and reduction atrioplasty. Both surgical techniques have since evolved to reduce their observed early mortality rates, and the long-term outcomes for each have been published. ${ }^{5,6}$

Contemporary surgeons caring for these infants face a difficult decision: Opt for BVR or pursue single-ventricle palliation. There are numerous flowcharts to offer guidance in decision making, yet each chart is skewed with the personal preferences of its author. ${ }^{7-10}$ Some have even advocated for the select use of a third option; that is, isolated systemic to pulmonary shunt. There remains no clear consensus regarding these choices. What we know for certain is that these children face a mortality of $100 \%$ without intervention. ${ }^{11}$ We believe in the superiority of Starnes palliation for several reasons: applicability across a wide spectrum of anatomy, consistent physiology, and simplicity. These factors translate into its reproducibility, reliable clinical outcomes, and heavy representation in our own management algorithm of the newborn infant diagnosed with Ebstein anomaly (Figure 1).

Carpentier simplified the anatomic classification of Ebstein patients into 4 major types increasing in severity from $\mathrm{A}$ to $\mathrm{D} .^{12}$ Actual clinical presentations are rarely that straightforward. Each Ebstein heart possesses a unique variety of the malformation that can usually be categorized 
according to the type with which it shares the majority of features. The single feature that must be present is a dysfunctional tricuspid valve due to failed leaflet delamination. Anatomic diversity stems from the degree to which delamination failed. This determines how displaced the tricuspid annulus is toward the RV apex and outflow tract. As the annulus moves farther away from its true location, the RA and atrialized RV sizes increase, RV outflow tract obstruction worsens, and functional RV cavity size decreases. ${ }^{13}$ The resultant influence on true/functional $\mathrm{RV}$ size is the basis for many authors' argument that Ebstein anomaly is not an isolated valvular disease. Instead, it is also an RV myopathy. An advantage of Starnes palliation is that it can be dependably applied despite anatomic diversity. From the most severe Ebstein defect to a child born with isolated tricuspid dysplasia and pulmonary atresia (a separate congenital tricuspid valve disease), Starnes procedure is effective at producing consistent postoperative anatomy equivalent to tricuspid atresia status postsystemic to pulmonary shunting.

Understanding the anatomic variability within Ebstein anomaly is important because it is directly linked to clinical outcomes. Two scoring systems demonstrating this correlation are cardiothoracic ratio and Great Ormond Street (GOS) echocardiography score. Cardiothoracic ratio is the maximal horizontal diameter of the cardiac silhouette divided by the maximal horizontal thoracic diameter measured from contralateral edges of pleura. GOS echocardiography score is calculated as the sum of areas of the RA and atrialized RV divided by the sum of the true RV, left atrium, and LV areas. Cardiothoracic ratio $>0.65$ and/or a GOS score $>1$ is prognostic for mortality in symptomatic neonates. $^{14,15}$ These associations reflect the pathologic interplay between anatomy and physiology: Bad anatomy creates bad physiology that results in bad outcomes. Any effective surgical intervention should alter this cascade.

We believe a neonatal Ebstein operation should have 3 major goals: decompress the RV; eliminate interventricular septal shift that diminishes LV filling, function, and outflow; and secure a source of pulmonary blood flow. In theory, Starnes procedure and BVR achieve all 3 aims and establish suitable physiology, albeit in opposite manners. Isolated Blalock-Taussig shunt only addresses the third, while relying on native cardiac anatomy and function to achieve the first and second aims. It is our opinion that single-ventricle palliation secures the goals with greater fidelity. The reason for this is the combination of 2 features inherent to critically ill neonates with Ebstein anomaly: elevated pulmonary vascular resistance and associated RV myopathy.

Starnes palliation decompresses the RV retrograde into a via fenestrated patch closure of the tricuspid valve orifice. This reduces RV inflow and encourages egress of blood back into the RA to be directed into systemic circulation.
The ventricular septum shifts rightward and cardiac output improves. Pulmonary blood flow is established with systemic to pulmonary shunt. In contrast, BVR relies on a diminished functional $\mathrm{RV}$ to decompress itself into the neonatal pulmonary vascular bed for adequate gas exchange and LV preloading. The RV is subsequently expected to reduce in size and allow for interventricular septal balancing. A competent tricuspid valve is an important feature to encourage forward flow and prevent unnecessary volume loading of the right side of the heart.

We recognize that the intended physiology of newborn infant's BVR is achievable. In fact, it has been proven in the many neonates who have successfully undergone tricuspid repair in published series. We, however, question its consistency and reliability. The most dramatic example of the failure of this flawed physiology is found in neonates with pulmonary atresia who undergo BVR with RV outflow tract transannular patch. ${ }^{12}$ The RV of these children inherits a simultaneous pressure and volume load that it is incapable of handling due to its underlying myopathy. This is well reflected in an observed mortality rate near $50 \%$ among this group.

In contrast, Starnes palliation importantly uncouples pulmonary blood flow from the RV. The systemic to pulmonary shunt overcomes elevated PVR and provides a means for gas exchange. The size of the true RV becomes irrelevant. It is not essential for pulmonary blood flow or systemic cardiac output. Instead, the ventricle reliably decompresses into the low-pressure venous circulation. Before 2001, we did not fenestrate tricuspid valve patches. We relied on the native pulmonary valve or small RV to PA homografts (in the setting of pulmonary atresia) for antegrade RV decompression. Results were inconsistent and unacceptable levels of mortality persisted for newborn infants who underwent palliation. This all fortuitously changed in a moribund patient with pulmonary atresia who had recalcitrant RV dilation after exclusion and RV to PA conduit placement. We returned to the operating room and fenestrated the tricuspid patch. The RV decompressed, and the patient survived.

Clinical outcomes support our opinion that the consistent anatomy and physiology of single-ventricle palliation is advantageous. Starnes procedure short- and long-term outcomes demonstrate 1-, 5-, and 10-year survival in a 27 patient cohort of $81 \%, 81 \%$, and $76 \%$, respectively. If you exclude 3 patients who had a nonfenestrated tricuspid valve patch (inferior physiology), 1-, 5-, and 10-year survival rose to $87 \%, 87 \%$, and $81 \%$, respectively. This group highlights important anatomic changes that occur when the $\mathrm{RV}$ is effectively decompressed: nonfunctional RA and RV regress in size and the septum continues to shift away from the LV. In our population of newborn infants status after Starnes palliation, median cardiothoracic ratio dropped from 0.8 to 0.68 , median GOS echocardiography score 

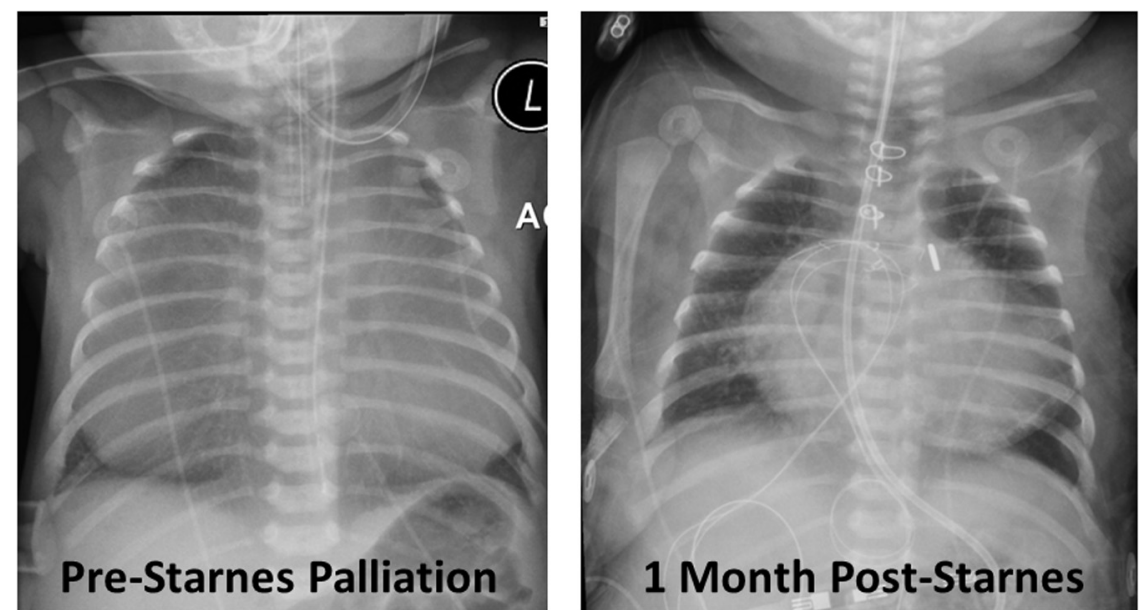

1

2.5
Cardiothoracic Ratio Great Ormond Street Echo Score
0.79

0.73

FIGURE 2. Preoperative and 1 month postoperative chest radiograph on a newborn who underwent Starnes palliative operation. Initial cardiothoracic ratio and Great Ormond Street echocardiography score predicted near $100 \%$ mortality. The patient survived and demonstrated a subsequent reduction in right atrium and right ventricle size with adequate decompression via atrial septectomy and fenestrated tricuspid valve closure.

dropped from 1.4 to 0.58 , and median septal impingement ratio improved from 0.5 to 0.82 immediately following initial surgery. ${ }^{3}$ We have observed these changes throughout the anatomic spectrum. It is most striking to see in the most severely affected newborns (Figure 2).

Tricuspid valve repair for biventricular circulation in the neonatal period demonstrated early and long-term survival of $71 \%$ in a cohort of 32 neonates. Early survival is heavily influenced by the presence or absence of anatomic pulmonary atresia: $56 \%$ versus $92 \%$ between these 2 subcohorts. ${ }^{12}$ There appear to be no late deaths at 15 years after BVR. ${ }^{4}$ Other groups have found it difficult to replicate these results. In a recent multicenter examination of outcomes, neonatal tricuspid valve repair carried a $42 \%$ rate of mortality. ${ }^{16}$ In the most dismal report in the literature, Shinkawa and colleagues ${ }^{6}$ report a $75 \%$ mortality for neonatal BVR. They have abandoned the approach in favor of single-ventricle palliation either via RV exclusion or isolated systemic to pulmonary shunt.

We believe the role for isolated shunt in the management of newborn infants with Ebstein anomaly to be limited (Figure 1). The ideal neonate has a reasonably sized functional RV and pulmonary stenosis but failed weaning from prostaglandin due to cyanosis alone. If an attempt is made to apply isolated shunt across a wider anatomic spectrum, results appear to be poor. Recent multicenter evaluation demonstrated early mortality of $48 \%$ for isolated shunt compared with $0 \%$ for Starnes palliation. ${ }^{14}$ This likely reflects a separate but important concept: This population of newborn infants leaves little room for initial errors in judgment.

One may argue that the reason for the disparity amongst observed outcomes is the expertise required to perform neonatal tricuspid valve repair. Tissues are delicate, the valve is severely malformed, and significant experience is required to understand how to create a competent valve without multiple crossclamps. In addition, it is difficult to predict eventual valvular function in a flaccid heart when eventual competency relies heavily on subvalvar apparatus interactions with a beating ventricle. Reported outcomes clearly demonstrate that the skillset necessary to effectively perform neonatal tricuspid valve repair does not widely exist. We propose that it cannot. Approximately 30 newborn infants nationwide require surgery for Ebstein anomaly each year. ${ }^{17}$ The rarity of this clinical presentation, low volume of operative cases per center, hemodynamic instability of the patient population, and the difficulty of transferring such patients to quaternary centers all argue that the most effective surgical option should be simple, reproducible, and expedient. These are characteristics favoring RV exclusion over BVR.

An ageing population of Fontan recipients has demonstrated the severe limits and long-term consequences of total passive pulmonary blood flow. Most congenital heart surgeons now aggressively pursue biventricular circulation for all patients across the full spectrum of anatomic malformations. Admittedly, there are rare subsets of newborn infants with adequately sized RVs and patent RV outflow tracts who are candidates for neonatal BVR (Figure 1). 
Although it is admirable to push them down this pathway, the limits of this approach as outlined above should make one pause to consider the early associated risks. Not to forget, BVR in a neonate carries its own long-term hazards such as the need for multiple valve reinterventions and pacemaker exchanges that have the potential to negatively influence both survival and quality of life.

A new and relevant point to consider when intervention is required for a critically ill neonate with Ebstein anomaly is that Starnes palliation is no longer considered a final commitment to Fontan circulation. Recent reports suggest the possibility of conversion to either 1.5 ventricle or biventricular circulation 5 to 17 months after RV exclusion. ${ }^{18}$ This offers an alternative pathway for the children who survive the newborn period. DaSilva and colleagues identify an important point that we have witnessed in clinical practice as well; that is, the excluded RV favorably remodels. They demonstrated a capacity for the excluded RV to generate a systolic pressure $>40 \mathrm{~mm} \mathrm{Hg}$ on catheterization. We have personally observed that the RV generates increasing pressure gradients over time on echocardiogram (measured by the jet of blood moving through the fenestration). In addition, the time away from the newborn period allows a patient's lungs to mature and the pulmonary arteries to grow. The combination of these changes results in a more capable RV that will face significantly less demand on its performance.

Our experience with these newborn infants reaffirms our belief regarding neonatal surgery: The most straightforward approach is usually the best. Starnes palliation is simple and reproducible. It delivers consistent anatomy and physiology across the wide spectrum of disease observed in neonates with Ebstein anomaly. Superior clinical outcomes reflect these advantages, and we believe it to represent the best interventional option currently available. We offer a firm recommendation to utilize RV exclusion and initial single-ventricle palliation of critically ill newborn infants with Ebstein anomaly.

\section{Conflict of Interest Statement}

The authors reported no conflicts of interest.

The Journal policy requires editors and reviewers to disclose conflicts of interest and to decline handling or reviewing manuscripts for which they may have a conflict of interest. The editors and reviewers of this article have no conflicts of interest.

\section{References}

1. Freud LR, Escobar-Diaz MC, Kalish BT, Komarlu R, Puchalski MD, Jaeggi ET, et al. Outcomes and predictors of perinatal mortality in fetuses with Ebstein anomaly or tricuspid valve dysplasia in the current era: a multicenter study. Circulation. 2015;132:481-9.

2. Freud LR, McElhinney DB, Kalish BT, Escobar-Diaz MC, Komarlu R, Puchalski MD, et al. Risk factors for mortality and circulatory outcome among neonates prenatally diagnosed with Ebstein anomaly or tricuspid valve dysplasia: a multicenter study. J Am Heart Assoc. 2020;9:e016684.

3. Starnes VA, Pitlick PT, Bernstein D, Griffin ML, Choy M, Shumway NE. Ebstein's anomaly appearing in the neonate. A new surgical approach. $J$ Thorac Cardiovasc Surg. 1991;101:1082-7.

4. Knott-Craig CJ, Overholt ED, Ward KE, Razook JD. Neonatal repair of Ebstein's anomaly: indications, surgical technique, and medium-term follow-up. Ann Thorac Surg. 2000;69:1505-10.

5. Kumar SR, Kung G, Noh N, Castillo N, Fagan B, Wells WJ, et al. Single-ventricle outcomes after neonatal palliation of severe ebstein anomaly with modified starnes procedure. Circulation. 2016;134:1257-64.

6. Boston US, Goldberg SP, Ward KE, Overholt ED, Spentzas T, Chin TK, et al. Complete repair of Ebstein anomaly in neonates and young infants: a 16-year follow-up. J Thorac Cardiovasc Surg. 2011;141:1163-9.

7. Knott-Craig CJ, Goldberg SP, Ballweg JA, Boston US. Surgical decision making in neonatal Ebstein's anomaly: an algorithmic approach based on 48 consecutive neonates. World J Pediatr Congenit Heart Surg. 2012;3:16-20.

8. Shinkawa T, Polimenakos AC, Gomez-Fifer CA, Charpie JR, Hirsch JC, Devaney EJ, et al. Management and long-term outcome of neonatal Ebstein anomaly. J Thorac Cardiovasc Surg. 2010;139:354-8.

9. Sano S, Fujii Y, Kasahara S, Kuroko Y, Tateishi A, Yoshizumi K, et al. Repair of Ebstein's anomaly in neonates and small infants: impact of right ventricular exclusion and its indications. Eur J Cardiothorac Surg. 2014;45:549-55.

10. Sainathan S, da Fonseca da Silva L, da Silva JP. Ebstein's anomaly: contemporary management strategies. J Thorac Dis. 2020;12:1161-73.

11. Watson H. Natural history of Ebstein's anomaly of tricuspid valve in childhood and adolescence. An international co-operative study of 505 cases. Br Heart J. 1974;36:417-27.

12. Carpentier A, Chauvaud S, Macé L, Relland J, Mihaileanu S, Marino JP, et al. A new reconstructive operation for Ebstein's anomaly of the tricuspid valve. $J$ Thorac Cardiovasc Surg. 1988;96:92-101.

13. Stephens EH, Dearani JA, Qureshi MY, Ammash N, Maleszewski JJ. The congenital tricuspid valve spectrum: from Ebstein to dysplasia. World J Pediatr Congenit Heart Surg. 2020;11:783-91.

14. Celermajer DS, Cullen S, Sullivan ID, Spiegelhalter DJ, Wyse RK, Deanfield JE. Outcome in neonates with Ebstein's anomaly. J Am Coll Cardiol. 1992;19: 1041-6.

15. Celermajer DS, Dodd SM, Greenwald SE, Wyse RK, Deanfield JE. Morbid anatomy in neonates with Ebstein's anomaly of the tricuspid valve: pathophysiologic and clinical implications. J Am Coll Cardiol. 1992;19:1049-53.

16. Knott-Craig CJ, Kumar TK, Arevalo AR, Joshi VM. Surgical management of symptomatic neonates with Ebstein's anomaly: choice of operation. Cardiol Young. 2015;25:1119-23.

17. Goldberg SP, Jones RC, Boston US, Haddad LM, Wetzel GT, Chin TK, et al. Current trends in the management of neonates with Ebstein's anomaly. World J Pediatr Congenit Heart Surg. 2011;2:554-7.

18. Da Silva JP, Viegas M, Castro-Medina M, Da Silva LD. The Da Silva cone operation after the starnes procedure for Ebstein's anomaly: new surgical strategy and initial results. J Thorac Cardiovasc Surg Tech. 2020.

Key Words: Ebstein anomaly, neonatal cardiac surgery, single ventricle palliation 